\title{
The association between parental mental health and behavioral disorders in pre-school children
}

Mansoureh Karimzadeh ${ }^{1}$, Mohammad Rostami ${ }^{2}$, Robab Teymouri ${ }^{3}$, Zahra Moazzen ${ }^{4}$, Siyamak Tahmasebi ${ }^{5}$

${ }^{1}$ Ph.D. Assistant Professor, Pediatric Neurorehabilitation Research Center, Department of Preschool Education, School of Educational Science and Social Welfare, University of Social Welfare and Rehabilitation Sciences, Tehran, Iran

2 Ph.D. Student, Department of Counseling, School of Behavioral Science, University of Social Welfare and Rehabilitation Sciences, Tehran, Iran

${ }^{3} \mathrm{Ph} . \mathrm{D}$. of Linguistics, Research Expert, Pediatric Neurorehabilitation Research Center, University of Social Welfare and Rehabilitation Sciences, Tehran, Iran

${ }^{4}$ M.Sc., Department of Preschool Education, School of Educational Science and Social Welfare, University of Social Welfare and Rehabilitation Sciences, Tehran, Iran

${ }^{5}$ Ph.D., Assistant Professor, Department of Preschool Education, School of Educational Science and Social Welfare, University of Social Welfare and Rehabilitation Sciences, Tehran, Iran

\section{Type of article: Original}

\begin{abstract}
Background and Aim: Behavioral disorders among children reflect psychological problems of parents, as mental illness of either parent would increase the likelihood of mental disorder in the child. In view of the negative relationship between parents' and children's illness, the current study intended to determine the correlation between mental health of parents and behavioral disorders of pre-school children.

Methods: The present descriptive-correlational research studied 80 children registered at pre-school centers in Pardis Township, Tehran, Iran during 2014-2015 using convenience sampling. The research tools included General Health Questionnaire (GHQ) and Preschool Behavior Questionnaire (PBQ). The resulted data were analyzed using Pearson Product-moment Correlation Coefficient and regression analysis in SPSS 21.

Results: The research results showed that there was a significant positive correlation between all dimensions of mental health of parents with general behavioral disorders $(p<0.001)$. The results of the regression analysis showed that parents' depression was the first and the only predictive variable of behavioral disorders in children with $26.8 \%$ predictive strength.

Conclusion: Given the strong relationship between children's behavioral disorders and parents' general health, and the significant role of parents' depression in children's behavioral disorders, it seems necessary to take measures to decrease the impact of parents' disorders on children.

Keywords: General health, Behavioral disorders, Preschool children
\end{abstract}

\section{Introduction}

Preschool years have a vital role in growth and adaptation of a child's future. Studying the behavioral and psychological disorders and incompatibility of children has gained attention during the recent decades. Researches have shown that $9.5-14.5 \%$ of under-five children experience social and emotional problems which affect their functioning, growth and educational preparedness. Moreover, $9 \%$ of the children who receive specialty mental health services in the United States are about 6 years old (1). Parents, particularly the mother, are the first with whom the newborn builds a relationship, thus they play the most important role in developing mental and emotional characteristics of the child and they significantly contribute to child's health or illness (2). Health, which is referred

\section{Corresponding author:}

Dr. Siyamak Tahmasebi, Department of Preschool Education, School of Educational Science and Social Welfare, University of Social Welfare and Rehabilitation Sciences, Tehran, Iran.

Tel: +98.2122180153, Fax: +98.2122180153, Email: siyamak.tahmasebi@gmail.com

Received: July 02, 2016, Accepted: January 25, 2017, Published: June 2017

iThenticate screening: December 09, 2016, English editing: February 09, 2017, Quality control: March 15, 2017

(C) 2017 The Authors. This is an open access article under the terms of the Creative Commons Attribution-NonCommercialNoDerivs License, which permits use and distribution in any medium, provided the original work is properly cited, the use is non-commercial and no modifications or adaptations are made. 
to as "a state of complete physical, mental, and social well-being" by the World Health Organization (WHO), has attracted many researchers, and recent investigations have revealed a strong relationship between general health and personal and psychological characteristics $(3,4)$. Mental health is an expression used for describing the cognitive and emotional levels of well-being as well as lack of psychological disorder. According to the holistic view and positive psychology, mental health means one's ability to enjoy life, create balance between daily activities and attempt to achieve psychological well-being (5). The WHO does not only consider mental health as the lack of psychological disorders, but it also takes it as a state of well-being according to which, every person considers themselves as strong and talented, capable of coping with natural stresses in life, and as an effective and successful person who can contribute to society (6). Children with behavioral disorders, not only interact with their parents but they also affect other family members, such as siblings. Studies have shown that behavioral disorders in children are closely associated with parents' psychological problems (2). In other words, the more severe the parents' psychological problems, the earlier the children's behavioral disorders emerge (7). Studies that have investigated the impact of family interactive patterns in creation of behavioral and emotional problems in children, have considered behavioral disorders as a child's reaction against family problems on the one hand (8), and against numerous inappropriate environmental stimuli such as rejecting the child, inadequate parents' affection and support, excessive kindness, family's aimlessness and coldness, lack of maternal love and care, insecure childhood attachment, and parents' stress on the other hand $(9,10)$. Research findings have also emphasized the importance of parents' health on a child's wellbeing, as a negative interaction between parents' and children's illness would most probably occur when both suffer from the same disorder. Mental disorder of a parent increases the risk of children's psychological problems (2). Other studies investigating parents' role in children's behavioral problems have shown that parents' role, lifestyle, family conflicts, and mothers' depression can effectively predict behavioral disorders in children. Fewer behavioral disorders were observed in children whose mothers had better experience in upbringing their children, had less depression, and tried to solve family conflicts (11). Generally, studies have revealed a high correlation between children's behavioral disorders and parents' mental disorders (2), mothers' mental stress (9, 12), mothers' poor mental health (5), mothers' irrational beliefs (13), parenting stress (14), poor child-parent interaction (10), depression $(7,15-17)$ caused by economic problems, social (18) and cultural (19) pressures, and parenting styles (20). Therefore, environmental stress factors (in parents) can create psychological disorders and many other complications for children. The objective of the present study was to determine the relationship between parents' mental health and behavioral disorders in pre-school children in Tehran, considering the following issues: the importance of parents' role in child's growth and development, the impact of behavioral disorders in forming child's characteristics, necessity of developing educational/preventive programs to recognize predictive variables, and decrease the rate of behavioral problems in children at younger ages. Also, based on our knowledge, there are very few studies on behavioral disorders in pre-school Iranian children. Therefore, the lack of information may partly be compensated.

\section{Material and Methods}

\subsection{Setting and Participants}

The present descriptive-correlational research studied 80 children aged 5-6 years who had registered in pre-school centers in Pardis Township, Tehran, Iran during 2014-2015. A simple random sampling method was employed by drawing names of the children and their parents, using the existing lists at the centers. Then a General Health Questionnaire (GHQ) and Preschool Behavior Questionnaire (PBQ) were filled out by mothers.

\subsection{Instruments}

The GHQ was initially developed by Goldberg in 1972 to recognize psychological problems in different settings. The questionnaire assesses the mental status of an individual during the previous month. Questions have been selected considering four subscales: 1- Melancholy (items on somatic symptoms); 2- anxiety/insomnia; 3- social dysfunction; 4- depression. This study used the 28-item short form with 4-point Likert scale (0-1-2-3). The cutoff point of the questionnaire divides people into healthy people if they score lower than 21 and people with a disorder if they score over 22. Goldberg's meta-analysis showed that the mean sensitivity and specificity of the questionnaire was 0.84 and 0.82 , respectively. The Cronbach's alpha was reported $0.84,0.85,0.79,0.81$, and 0.91 respectively for somatic symptoms, anxiety, social dysfunction, depression, and general health (21). Iranian studies reported Cronbach's alpha for the same variables as $0.80,0.89,0.83,0.80$, and 0.87 respectively, which are indicative of good internal consistency of this questionnaire (22). We calculated Cronbach's alpha as 0.929. PBQ has 28 threepoint items scoring 0,1, and 2, indicative of "doesn't apply", "applies sometimes", and "frequently applies". A higher score indicates higher levels of behavioral disorders in the child. PBQ was validated using factor analysis. The results showed that PBQ comprises three scales: 1-aggression explains 0.58 of the variance with factor loading 
from 0.72 to 0.33 ; 2- ignorance and childish behavior has a variance of 0.24 with factor loading from 0.79 to 0.26 ; 3 - withdrawal and anxiety with a variance of 0.18 with factor loading from 0.60 to 0.32 . The test-retest technique was used to measure the reliability of the questionnaire. The test-retest coefficient was found as $0.89,0.80,0.70$, and 0.88 respectively for aggression, ignorance and childish behaviors, withdrawal and anxiety, and whole scale (23). Cronbach's alpha was calculated as 0.863 in the current study. The inclusion criteria included the following: the ability to read and write for parents, parents' and children's informed consent and willingness to participate in the study, and the exclusion criteria included lack of history of psychosis (based on the interview).

\subsection{Research Ethics and Procedures}

The ethical considerations of the study included: 1- a comprehensive explanation of the research subject and study procedure was provided to authorities and participants; 2- the data were considered confidential and used exclusively by the researcher; 3- the participants were assured of the confidentiality of their information; 4participants were informed of their test score if they requested it; 4- the interviews and questionnaire distribution were scheduled so as not to disrupt mothers' daily activities, and 5-participants had the right to withdraw any time they felt uncomfortable. After obtaining school authorities' permission, taking into account ethical considerations, and informing authorities and parents, the parents' and children's consents were obtained for participating in the study.

\subsection{Statistical Analysis}

The data collection was implemented through the questionnaires. Then the data was analyzed using Pearson Product-moment Correlation Coefficient and multiple regression analysis in IBMC SPSS $\odot$ Statistics version 21 (IBMC Corp., Armonk, NY, USA) (24).

\section{Results}

The studied variables included three dimensions of behavioral disorders for children (Aggression, ignorance and childish behavior, withdrawal and anxiety) and four dimensions of parents' mental health (Physical functioning, anxiety, social functioning, depression). Their means and standard deviations are presented in Table 1 . The highest mean score related to the dimensions of behavioral disorders in children was for aggression $(m=0.348, S D=2.28)$. The highest mean score related to the dimensions of parents' mental health was for depression $(\mathrm{m}=0.697, \mathrm{SD}=3.54)$. The results of Pearson Product-moment Correlation Coefficient (Table 2) on the relationship between general health and its dimensions with behavioral problems in children showed that the significance level for correlation between behavioral disorders with each of the parents' general health dimensions, was zero. Parents' depression had the highest correlation with behavioral disorders in children with coefficient of 0.517 at a level of confidence less than 0.001 , while social functioning had the lowest correlation with coefficient of 0.324 at the same level of confidence. The regression model used for data analysis was a concurrent model. The results showed that the dimensions of mothers' general health totally, determined $28.7 \%$ of the variance of children's behavioral disorders while the estimated standard error was $23.6 \%$. Analyzing ANOVA of the regression model, the calculated F-value was at confidence level less than 0.001 . In other words, a combination of parents' general health dimensions can be a significant predictor for behavioral disorders in children. According to Table 3 and resulted regression coefficients, t-test proved to be insignificant for the three variables of physical functioning, anxiety, and social functioning. Moreover, parents' depression had the highest regression impact on children's behavioral disorders. In other words, an increase of a standard deviation in parents' depression increases behavioral disorders 0.400 of a standard deviation, and vice versa. Stepwise regression model was used for depression. Results of analysis showed that parents' depression is the first and only predictor of behavioral disorders in children as $26.8 \%$ of their behavioral problems are so affected.

Table 1. The mean and standard deviation of parenting dimensions in addicted and non-addicted mothers

\begin{tabular}{|l|l|l|l|}
\hline Variable & Dimensions & $\mathrm{n}$ & Mean (SD) \\
\hline Behavioral problems of children & Aggression & 80 & $0.348(2.28)$ \\
\cline { 2 - 4 } & Ignorance and childish behavior & 80 & $0.339(2.43)$ \\
\cline { 2 - 4 } & Withdrawal and anxiety & 80 & $0.324(2.45)$ \\
\hline \multirow{4}{*}{ General health of parents } & Physical functioning & 80 & $0.546(3.25)$ \\
\cline { 2 - 4 } & Anxiety & 80 & $0.583(3.27)$ \\
\cline { 2 - 4 } & Social functioning & 80 & $0.460(2.60)$ \\
\cline { 2 - 4 } & Depression & 80 & $0.697(3.54)$ \\
\hline
\end{tabular}


http://www.ephysician.ir

Table 2. Pearson Product-moment Correlation Coefficient on the relationship between parenting dimensions and behavioral problems

\begin{tabular}{|l|l|l|}
\hline Dimensions of parents' General health & Evaluated index & Behavioral disorders in children \\
\hline Physical functioning & Correlation coefficient & $0.425^{* *}$ \\
\cline { 2 - 3 } & p-value & 0.000 \\
\cline { 2 - 3 } & Number & 80 \\
\hline \multirow{4}{*}{ Social functioning } & Correlation coefficient & $0.324^{* *}$ \\
\cline { 2 - 3 } & p-value & 0.000 \\
\cline { 2 - 3 } & Number & 80 \\
\hline \multirow{3}{*}{ Anxiety } & Correlation coefficient & $0.407^{* *}$ \\
\cline { 2 - 3 } & p-value & 0.000 \\
\cline { 2 - 3 } & Number & 80 \\
\hline \multirow{2}{*}{ Depression } & Correlation coefficient & $0.517^{* *}$ \\
\cline { 2 - 3 } & p-value & 0.000 \\
\cline { 2 - 3 } & Number & 80 \\
\hline
\end{tabular}

Table 3. Regression coefficients of variables

\begin{tabular}{|l|l|l|l|l|l|}
\hline \multirow{2}{*}{ Variable } & Unadjusted coefficients & Adjusted coefficients & \multirow{2}{*}{$\mathrm{t}$} & \multirow{2}{*}{ Significance level } \\
\cline { 2 - 6 } & $\mathrm{B}$ & $\mathrm{SD}$ & Beta & & \\
\hline Constant value & 1.542 & 0.188 & - & 82.215 & 0.000 \\
\hline Physical functioning & 0.088 & 0.077 & 0.176 & 1.140 & 0.258 \\
\hline Social functioning & 0.015 & 0.079 & 0.032 & -0.188 & 0.852 \\
\hline Anxiety & 0.033 & 0.069 & 0.056 & 0.485 & 0.629 \\
\hline Depression & 0.157 & 0.058 & 0.400 & 2.728 & 0.008 \\
\hline
\end{tabular}

\section{Discussion}

This study evaluated the relationship between parents' mental health and behavioral problems in pre-school children, and the results were indicative of a positive relationship between the two. The findings were also aligned with other studies $(2,5,9,10,12,13,25)$. It can be said that some parenting preferences are associated with emergence of maladaptive behavior in children (26). Numerous studies on parents' attitude toward children and their parenting styles reveal that parenting styles have a long-term impact on behavior, expectations, and consequently the characteristics of individuals in the future (20). Besides parenting styles, low levels of education, parents' young age, economic problems, social problems, parents' physical abuse during their own childhood (18), and cultural beliefs (19) play important roles in emergence of behavioral problems in children. In fact, lack of parents' attention to provide a psychologically and emotionally healthy environment for children and adolescents, and lack of good relationship, exposes children to emotional deficiencies and psychological and behavioral problems. Moreover, it seems that certain parental conflicts and difficulties such as managing children's normal behavior (27), routine problems such as feeding, sleep, or illnesses (28) tend to distress parents such that parenting and resulting pressures can lead to a significant maladaptation in parents, especially mothers. Parents who experience high levels of parenting stress are sensitive toward any changes in their children. Thus, they assume the situation is out of control if they are exposed to problems such as feeding, sleep, infections, diseases, and usual misbehavior. Therefore, they try to overcome the problems and control the situation through overprotection or exercising discipline and order that adversely creates or worsens behavioral problems in children $(14,29)$. Children are susceptible to mental disorders and studies show that one of the causes of their mental harm is the nature of parent-child interaction, particularly with sick parents. This is more evident in Iranian families where children have more interaction with mothers who are mostly housewives, and children are limited in their social interactions and might experience family as their only social environment until they go to school. So, many behavioral patterns and their characteristics are formed in their interaction with family. This increases the risk of inducing parents' problems and disorders to the child and they acquire pathological behavior patterns (5). Studies show that primary school children whose parents suffer from poor mental health had also more severe behavioral-emotional problems in comparison with children having psychologically healthy parents (2). The results of the regression table also showed that depression was the only dimension of parents' general health that was a strong predictive variable for behavioral problems in pre-school children. The results are aligned with other studies $(5,7,15-17)$. The findings of the present research can be explained by the fact that besides the role of genetics in emergence of depression and anxiety disorders, inadequacy 
of maternal care due to their psychological problems such as depression, causes emotional trauma in the child, with regard to attachment theory. On the other hand, according to the social learning theory which relies on modeling the role, human interaction and replication, children can acquire automatic negative thoughts from their mothers. Children institutionalize negative cognition and thoughts toward themselves and their environment, and relate them to their surroundings $(2,30)$. The most important limitations of the present study were: the small sample size, not comparing mothers with fathers in terms of mental health, and not determining the impact of general health of each parent on children in terms of their gender.

\section{Conclusions}

In conclusion, it can be suggested that children often react quickly to life pressures, and their reactions change immediately after removal of the pressures. So, emergence of behavioral problems is the suggested way to react, as they are deeply dependent on parents and others and are physically and mentally immature. Thus, proper understanding of such a process and awareness of their own problems, together with development of parenting skills can help parents to decrease behavioral problems in children. Therefore, it is recommended to develop training programs in this regard. The most important limitations of the present study were: small sample size, not comparing mothers with fathers in terms of mental health, and not evaluating the impact of general health of each parent on children according to their gender.

\section{Acknowledgments:}

The authors would like to extend their deepest gratitude toward all mothers and pre-school children in Tehran. This article has not been extracted from the thesis and no financial support.

\section{Conflict of Interest:}

There is no conflict of interest to be declared.

\section{Authors' contributions:}

All authors contributed to this project and article equally. All authors read and approved the final manuscript.

\section{References:}

1) Barzegar $Z$, Pourmohamadrezatajrishi M, Behnia $F$. The effectiveness of playing on externalizing problems in preschool children with behavioral problems. International Journal of Behavioral Sciences. 2012; 6(4): 347-54.

2) Riahi F, Amini F, Salehi Veisi M. Children's behavioral problems and their relationship with maternal mental health. Journal of Jahrom University of Medical Sciences. 2010; 10: 41-6.

3) Schwartz CE, Bode R, Repucci N, Becker J, Sprangers MA, Fayers PM. The clinical significance of adaptation to changing health: a meta-analysis of response shift. Qual Life Res. 2006; 15(9): 1533-50. doi: 10.1007/s11136-006-0025-9. PMID: 17031503.

4) Biglar M, Hayati Y, Rahmani H, Rajabnezhad Z, Dargahi H. Study Of General Health Among Tehran University Of Medical Sciences Hospital's Administrators. Journal of Payavard Salamat. 2014; 8(1): 13-24.

5) Shirazi F, Rezvani S, Haghighi N, Farzamfar E. The Relationship between Mental Health Disorders with Anxiety and Depression in Mothers of Children. Cheshmandaz Amin in Applied Psychology. 2014; 1(1): 37-44.

6) WHO. Mental health. 2016. Available from: http://www.who.int/topics/mental_health/en/.

7) Narayanan MK, Naerde A. Associations between maternal and paternal depressive symptoms and early child behavior problems: Testing a mutually adjusted prospective longitudinal model. Journal of affective disorders. 2016; 196: 181-9. doi: 10.1016/j.jad.2016.02.020. PMID: 26922147.

8) Johnston C, Mash EJ. Families of children with attention-deficit/hyperactivity disorder: review and recommendations for future research. Clin Child Fam Psychol Rev. 2001; 4(3): 183-207. doi: 10.1023/A:1017592030434. PMID: 11783738.

9) Teymouri S, Ataei FR. Relationship Between Parental Stress and Children's Affective and Behavioral Disorder. Applied Psychology, 4 (16):17-26

10) Dubois-Comtois K, Bernier A, Tarabulsy GM, Cyr C, St-Laurent D, Lanctot AS, et al. Behavior problems of children in foster care: Associations with foster mothers' representations, commitment, and the quality of mother-child interaction. Child Abuse Negl. 2015; 48: 119-30. doi: 10.1016/j.chiabu.2015.06.009. PMID: 26187685. 
11) Koblinsky SA, Kuvalanka KA, Randolph SM. Social skills and behavior problems of urban, African American preschoolers: role of parenting practices, family conflict, and maternal depression. Am J Orthopsychiatry. 2006; 76(4): 554-63. doi: 10.1037/0002-9432.76.4.554. PMID: 17209723.

12) Ciciolla L, Gerstein ED, Crnic KA. Reciprocity among maternal distress, child behavior, and parenting: transactional processes and early childhood risk. J Clin Child Adolesc Psychol. 2014; 43(5): 751-64. doi: 10.1080/15374416.2013.812038. PMID: 23819445, PMCID: PMC3808475.

13) Salimi S, Ramezani A, Khavanaki Z, Amiri M. The Relationship Between Mothers'irrational Beliefs With Their Children's Behavioral Problems. Journal of Applied Psychology. 2009; 3(1): 46-57.

14) Tahmasian K, Anari A, Fathabadi M. Evaluation of Effective Maternal Characteristics in Behavioral Problems of 2-6 Years Old Children. Journal of Psychology. 2012; 26(7): 94-109.

15) Aunola K, Ruusunen AK, Viljaranta J, Nurmi J-E. Parental affection and psychological control as mediators between parents' depressive symptoms and child distress. Journal of Family Issues. 2015; 36(8): 1022-42. doi: 10.1177/0192513X13494825.

16) Dette-Hagenmeyer DE, Reichle B. Parents' depressive symptoms and children's adjustment over time are mediated by parenting, but differentially for fathers and mothers. European Journal of Developmental Psychology. 2014; 11(2): 196-210. doi: 10.1080/17405629.2013.848789.

17) Bagner DM, Pettit JW, Lewinsohn PM, Seeley JR, Jaccard J. Disentangling the temporal relationship between parental depressive symptoms and early child behavior problems: a transactional framework. J Clin Child Adolesc Psychol. 2013; 42(1): 78-90. doi: 10.1080/15374416.2012.715368. PMID: 22963145, PMCID: PMC4399760.

18) Li F, Godinet MT, Arnsberger P. Protective factors among families with children at risk of maltreatment: Follow up to early school years. Children and Youth Services Review. 2011; 33(1): 139-48. doi: 10.1016/j.childyouth.2010.08.026.

19) Ferrari AM. The impact of culture upon child rearing practices and definitions of maltreatment. Child Abuse Negl. 2002; 26(8): 793-813. doi: 10.1016/S0145-2134(02)00345-9. PMID: 12363332.

20) Wolfradt U, Hempel S, Miles JN. Perceived parenting styles, depersonalisation, anxiety and coping behaviour in adolescents. Personality and individual differences. 2003; 34(3): 521-32. doi: 10.1016/S0191$8869(02) 00092-2$.

21) Goldberg DP, Gater R, Sartorius N, Ustun TB, Piccinelli M, Gureje O, et al. The validity of two versions of the GHQ in the WHO study of mental illness in general health care. Psychol Med. 1997; 27(1): 191-7. PMID: 9122299.

22) Kabiry B, Shahri P, Azarnosh S, Hagheghizadeh M, Merfathi S. The Relationship between Mother's General Health and Growth of below-6-Month-Old Infants Referred to Health Centers of West of Ahvaz. Sadra Medical Sciences Journal. 2015; 3.

23) Sarihi N, pournesaei G, Nikakhlagh M. Effectiveness of group play therapy on behavior problems in preschool children. Journal of Analytical-Cognitive Psychology. 2015; 6(23): 4-35.

24) Weitzman M, Rosenthal DG, Liu YH. Paternal depressive symptoms and child behavioral or emotional problems in the United States. Pediatrics. 2011; 128(6): 1126-34. doi: 10.1542/peds.2010-3034.

25) Winsler A, Madigan AL, Aquilino SA. Correspondence between maternal and paternal parenting styles in early childhood. Early Childhood Research Quarterly. 2005; 20(1): 1-12. doi: 10.1016/j.ecresq.2005.01.007.

26) Kwok S, Wong D. Mental health of parents with young children in Hong Kong: The roles of parenting stress and parenting self-eÅcacy. Child and Family Social Work. 2000; 5: 57-65. doi: 10.1046/j.13652206.2000.00138.x.

27) Ostberg M, Hagekull B, Wettergren S. A measure of parental stress in mothers with small children: dimensionality, stability and validity. Scandinavian journal of psychology. 1997; 38(3): 199-208. doi: 10.1111/1467-9450.00028.

28) Solem MB, Christophersen KA, Martinussen M. Predicting parenting stress: Children's behavioural problems and parents' coping. Infant and Child Development. 2011; 20(2): 162-80. doi: 10.1002/icd.681.

29) Sadock BJ, Sadock VA. Kaplan and Sadock's synopsis of psychiatry: Behavioral sciences/clinical psychiatry: Lippincott Williams \& Wilkins; 2011. 